\title{
Assessment of the methodological and ethical quality of clinical trials published in family medicine journals
}

\author{
Alberto Castaño-García1, Francisco Guillén-Grima² and Pilar León-Sanz ${ }^{3}$ \\ ${ }^{1}$ Corella Health Center, Servicio Navarro de Salud, Corella, Navarra; ${ }^{2}$ Department of Preventive Medicine, Clínica Universidad de Navarra, \\ Pamplona, Navarra; Instituto de Investigación Sanitaria de Navarra (IdiSNA), Pamplona, Navarra; ${ }^{3}$ Faculty of Medicine, Department of Biomedical \\ Humanities, Universidad de Navarra, Pamplona, Navarra, Spain
}

\begin{abstract}
Objective: To evaluate some methodological and ethical quality variables of clinical trials (CTs) published in 10 family medicine journals. Methods: Quality descriptive study of 10 family medicine journals including CTs in humans published since 2010 to 2013. We obtained 141 CT and 2447 were excluded. Results: CTs parallels controlled in 92.9\% (95\% confidence interval [95\% Cl]: 92.0-93.9). Masked randomization in 72.3\% (95\% Cl: 71.7-73.1), decentralized in 51.8\% (95\% Cl: $51.4-52.4$ ) and using as control an active treatment in $82.2 \%$ (95\% Cl: 81.5-83.1). Wrote informed consent in 48.9\% (95\% Cl: 48.5-49.5) and it was not withdrawn in $56.0 \%$ of cases (95\% Cl: 55.5-56.7). Approval by clinical research ethics committee (CREC) in 134, and there was no conflict of interest in 117 CTs. Average $k$ was 0.96 (95\% Cl: 0.93-0.99). Conclusions: We observe an increase in some quality variables like masked randomization (19.6\%) and approval by CREC (75\%) post CONSORT, in CTs published in 10 family medicine journals (2010-2013).
\end{abstract}

KEY WORDS: Checklist. Clinical trials as topic. Family practice. Statistical analysis. Random allocation. Research ethics committee.

\section{Introduction}

In current research, randomized clinical trial is the reference method to assess new therapies or strategies in medicine ${ }^{1}$. Low quality in its design or publication ${ }^{2}$ might lead to risk underestimation or even misrepresentation when using treatments that might be less beneficial or even harmful ${ }^{3}$, with possible consequences in daily clinical practice.

There are diverse methods for clinical trials publications quality assessment ${ }^{4}$. Dechartres et al. ${ }^{5}$ identified 26 scales or checklists derived from the Consolidated Standards of Reporting Trials (CONSORT). They found an increase in information about methodological aspects, but only $29 \%$ of adequate concealed allocation, showing that quality assessment still has important problems. Current systematic reviews suggest that randomized clinical trials quality improvement is associated with the use of CONSORT guidelines ${ }^{6,7}$.

Cluster-type trials (randomization by groups), as compared with other individual trials with the same number of subjects, are poorly efficient and have less statistical power ${ }^{8}$.

To date, we haven't found any study that uses a checklist similar to that of CONSORT in journals of the family medicine specialty ${ }^{9}$, and hence we have developed a new, more accurate tool to try to delve into different aspects of methodological and ethical quality of clinical trials that are published in these journals.

The purpose is to quantitatively and qualitatively analyze some variables that represent part of the 
methodological and ethical quality of clinical trials published between 2010 and 2013 in the 10 journals of the family medicine specialty with the highest impact-factor that publish clinical trials.

\section{Methods}

A descriptive study was carried out on the quality of articles published in the 10 journals of the family medicine specialty with the highest impact that publish clinical trials.

A manual search was carried out in the following journals: Annals of Family Medicine, Atención Primaria, Australian Family Physician, BioMed Central Family Practice, British Journal of General Practice, Canadian Family Physician, European Journal of General Practice, Family Practice, Journal of American Board of Family Medicine and Scandinavian Journal of Primary Health Care.

In this cross-sectional review, the Preferred Reporting Items for Systematic Reviews and Meta-analyses (PRISMA) statement ${ }^{10}$ was taken as a basis, but only in the referred journals, as they are specific to the family medicine specialty, they publish clinical trials and have the highest impact-factor (Journal Citation Report). The search strategy in PubMed was carried out with the terms "((“"family practice") OR "general practice" OR "primary care" OR "family medicine") AND "clinical trial" AND "quality"), clinical trial, humans". We found 1096 articles, and reviewed those selected in Related citations of all articles up to two levels. In Web of Knowledge, we used the following search criterion: "Topic=("family practice") OR Topic=("general practice") OR Topic=("primary care") OR Topic=("family medicine") AND Topic=("clinical trial") AND Topic=("quality"), with the limits being adjusted to "Document Types=(CLINICAL TRIAL) AND Research Domains $=($ SCIENCE TECHNOLOGY) AND Research Areas $=($ HEALTH CARE SCIENCES SERVICES OR GENERAL INTERNAL MEDICINE)". We found 5749 studies. In the Google scholar search engine, the following search criterion was used: "((“family practice") OR "general practice" OR "primary care" OR "family medicine") AND "clinical trial" AND "quality")", with 20.600 articles being found. Finally, 1925 articles were retrieved in Scopus with the search criterion "(TITLE-ABS-KEY("family practice") OR TITLE-ABS-KEY("general practice") OR TITLE-ABS-KEY("primary care") OR TITLE-ABS-KEY("-family medicine") AND TITLE-ABS-KEY("clinical trial") AND TITLE-ABS-KEY("quality")) AND DOCTYPE (ar) AND
(LIMIT-TO (SUBJAREA,"MEDI"))". Pooling the three bibliographic sources, a total of 2588 original articles were obtained in the 10 journals selected for assessment.

Using a checklist, clinical trials published in the 10 journals of the family medicine specialty with the highest impact factor and that publish clinical trials were assessed. Annals of Family Medicine is the one with the highest impact-factor $(4.613)^{11}$. These journals follow the CONSORT guidelines ${ }^{4,12}$ and International Committee of Medical Journal Editors (ICMJE) recommendations ${ }^{13}$. The CONSORT ${ }^{4}$ and Helsinki ${ }^{14}$ declarations, which provide checklists ${ }^{13}$ with higher quality for the publication of clinical trials ${ }^{15}$, were followed.

Clinical trials conducted in human subjects, both patients and healthy volunteers, published between January 2010 and December 2013, were included. Since the CONSORT guidelines were first published in 2001, this study was subsequently carried out 0 in order to increase quality ${ }^{7,16}$.

A CONSORT18-based checklist ${ }^{17}$ with 80 items (8 sections), which were increased to 133 (11 sections), was updated. Following the Helsinki Declaration ${ }^{19}$ and the Pragmatic-Explanatory Continuum Indicator Summary (PRECIS $)^{20}$ graph, items were created or modified to adapt them to the family medicine specialty. More explicit variables that helped to more specifically identify the use of placebo in treatment comparisons were created. The Agency for Healthcare Research and Quality (AHRQ ${ }^{21}$ criteria,i.e. the Jadad scale, were introduced. An assessment was made for the existence of data and safety monitoring board (DSMB), stopping rules (Haybitt-le-Peto, Pocock, O'Brien-Fleming) ${ }^{22}$, futility analysis ${ }^{23}$, sequential and optimized-type trials, and clinical research ethics committee (CREC); also whether participating subjects' race or language were indicated. Granted incentives, authors' specific bioethics training, types of conflicts of interests and the influence of sponsors on the clinical trials were investigated.

Two authors (FGG and ACG) independently reviewed the 141 selected articles with the checklist. They used detailed instructions for the fulfillment of variables (items) and discrepancies were solved by consensus. Frequency, percentage and Clopper-Pearson $95 \%$ confidence interval $(\mathrm{Cl})^{24}$ were calculated ${ }^{24}$. The mean, median, mode, minimum, maximum, standard deviation and its $95 \% \mathrm{Cl}$ were also obtained for quantitative variables. Mean $\kappa$ and its $95 \% \mathrm{Cl}$ was obtained $^{25}$. The SPSS 20.0 statistical package was used. 


\section{Results}

A total of 141 clinical trials meeting the inclusion criteria were found (Fig. 1), since most studies were observational. The Journal of Family Practice did not publish any clinical trial during the study period.

The main methodological variables analyzed in this study are presented in table 1 . The results are presented as percentages or absolute numbers, as adequate, to highlight the data in question.

When completing table 1 , in the "Country of authors" section within the "Other Europeans" group, the most commonly found was the Netherlands (22 clinical trials), and in the group of "Others", it was Canada (14 clinical trials). As for "Continent of study", the most common country in Europe was the Netherlands (22), followed by the United Kingdom (11), Sweden (9), Spain (8) and Denmark (6); in the "Others" group, New Zealand stands out (3 clinical trials).

In the "Rationale and objectives" section of our checklist, the "clinical trial" denomination was observed to appear in the title or subtitle in 107, and it was considered to be uncertain (not specifically named) in 33; related clinical trials appeared in 135 and it was uncertain in 2; at least one systematic review was cited in 128 clinical trials and it was uncertain in 3; reference to previous publication of the same clinical trial appeared in 44, and priori hypothesis appears in all.

About the "Type of clinical trial", 54.6\% (95\% Cl: 54.1-55.2) were carried out in more than 5 centers, 19.1\% (95\% Cl: $19.0-19.4)$ in 5 or less centers, and $17.7 \%$ (95\% Cl: 17.6-18.0) were single-center trials. In $71.6 \%$ (95\% Cl: 71.0-72.4) some author was an epidemiologist or statistician, and acted as a collaborator in $14.9 \%$ (95\% Cl: 14.8-15.1).

As for "Clinical trial design", 92.9\% (95\% Cl: 92.093.9) were parallel-group controlled clinical trials, and 6 were factorial controlled trials. According to AHRQ criteria, there was higher tendency towards pragmatic rather than explicative clinical trials.

In 132 clinical trials, a baseline comparison was performed in a table, and the $P$-value appeared in $57.4 \%$ (95\% Cl: 56.9-58.1). No non-controlled clinical trials were found. Only the trial by Licciardone et al. ${ }^{26}$ was sequential and used the stopping rule (O'Brien Fleming). In no study did the PRECIS graph appear ${ }^{20}$, and neither were there optimized clinical trials. Concealment efficacy was only observed in 7 clinical trials. Withdrawals due to adverse effects were found in 11 clinical trials and were uncertain in 26 studies.

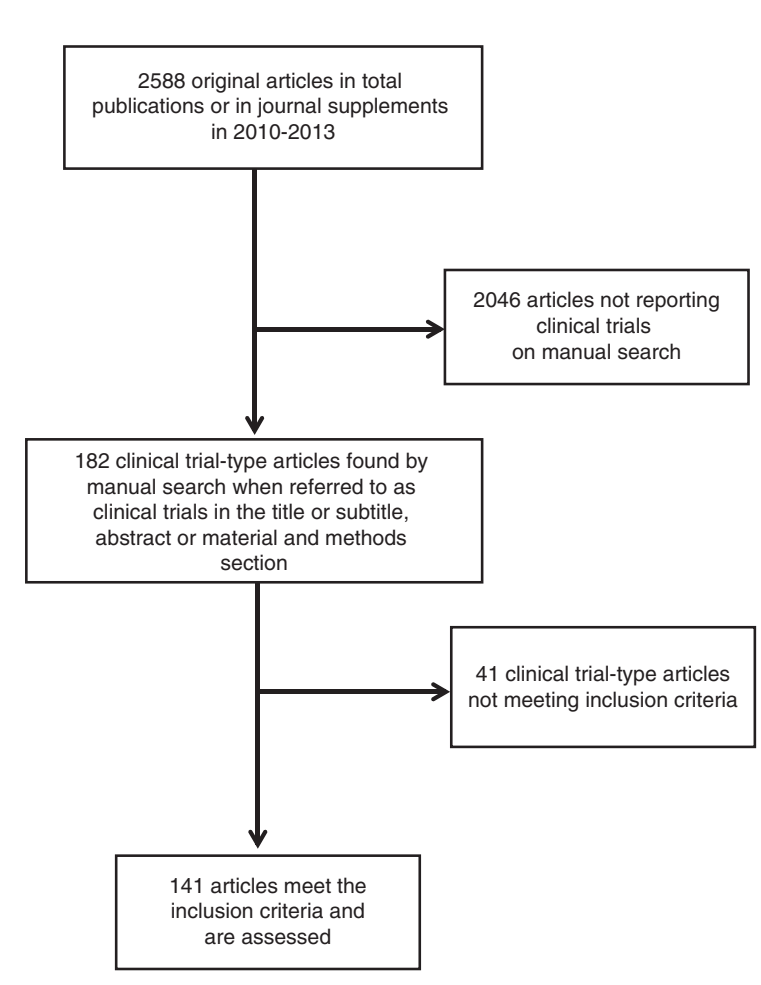

Figure 1. Cross-section review simplified flow diagram.

As for "Subject selection", Caucasian subjects were included in $27.0 \%$ (95\% Cl: 26.8-27.4), African Americans in $18.4 \%$ (95\% Cl: 18.3-18.7), Hispanics in $14.2 \%$ (95\% Cl: 14.1-14.4) and Asians in 11.3\% (95\% Cl: 11.2$11-5)$ in 16 studies. Ethnicity was not indicated in $71.6 \%$ (95\% Cl: $71.0-72.4)$, it was not specified in 25 clinical trials (17.7\%; $95 \% \mathrm{Cl}$ : 17.6-18.0) and, in 9, subjects were ethnic minorities, such as Native Americans and Vietnamese. Inclusion of immigrant or low income population has increased over the past 3 years (20 clinical trials), and "vulnerable" people were observed ${ }^{27}$.

In "Sample size", the methodological quantitative variables are indicated in table 2 . Their descriptive statistics and standard deviation $95 \% \mathrm{Cl}^{28}$ are shown in table 3.

The alpha error was $87.9 \%$ (95\% Cl: 87.1-88.8), beta error was $83.7 \%$ (95\% Cl: 82.9-84.6), the magnitude of the least difference to be found was $80.9 \%$ (95\% $\mathrm{Cl}$ : 80.2-81.8) and flow diagram was observed in 86.5\% (95\% Cl: 85.7-87.4).

As regards "Treatment description", with an efficacious standard treatment, placebo or no intervention was used as control in $79.4 \%(95 \% \mathrm{Cl}$ : $78.7-79.3)$. A sound and convincing methodological reason for using placebo or no intervention was given in 11 clinical trials, and the determination of efficacy and safety in 13. No study was found where the use of placebo 
Gaceta Médica de México. 2018;154

Table 1. Description of the sample and methodological variables: frequencies, percentages and $95 \%$ confidence intervals

\begin{tabular}{|c|c|c|c|c|}
\hline Variable & Value & Frequency & $\%$ & $95 \% \mathrm{Cl}$ \\
\hline \multirow[t]{6}{*}{ Authors' country } & USA & 36 & 25.5 & $25.3-25.8$ \\
\hline & United Kingdom & 11 & 7.8 & $7.8-7.9$ \\
\hline & Spain & 10 & 7.1 & $7.1-7.2$ \\
\hline & Scandinavia & 18 & 12.8 & $12.7-13.0$ \\
\hline & Other Europeans & 31 & 22.0 & $21.8-22.3$ \\
\hline & Other & 35 & 24.8 & $24.6-25.1$ \\
\hline \multirow[t]{6}{*}{ Continent where the study is carried out } & North America & 50 & 35.5 & $35.2-35.9$ \\
\hline & Latin America & 2 & 1.4 & 1.4-1.5 \\
\hline & Asia & 4 & 2.8 & $2.8-2.9$ \\
\hline & Australia & 8 & 5.7 & $5.7-5.8$ \\
\hline & Europe & 71 & 50.4 & $50.0-51.0$ \\
\hline & Other & 6 & 4.3 & 4.3-4.4 \\
\hline \multirow[t]{5}{*}{ Type of funding } & Non-profit: public & 78 & 55.3 & $54.8-55.9$ \\
\hline & Non-profit: private* & 71 & 50.4 & $50.0-51.0$ \\
\hline & Pharmaceutical industry* & 17 & 11.9 & $11.8-12.1$ \\
\hline & Not indicated & 8 & 5.7 & $5.7-5.8$ \\
\hline & None & 3 & 2.1 & $2.1-2.2$ \\
\hline \multirow[t]{8}{*}{ Randomization system } & Simple randomization & 49 & 34.8 & $34.5-35.2$ \\
\hline & Block randomization & 39 & 27.7 & $27.5-28.1$ \\
\hline & Stratified & 23 & 16.3 & $16.2-16.5$ \\
\hline & Paired & 5 & 3.6 & $3.6-3.7$ \\
\hline & Minimization* & 5 & 3.6 & $3.6-3.7$ \\
\hline & Cluster* & 46 & 32.5 & $32.3-32.9$ \\
\hline & Other* & 2 & 1.4 & $1.4-1.5$ \\
\hline & Non-randomized: simple & 4 & 2.8 & $2.8-2.9$ \\
\hline \multirow[t]{4}{*}{ Was there a concealed randomization method followed? } & Yes & 102 & 72.3 & $71.7-73.1$ \\
\hline & No & 23 & 16.3 & $16.2-16.5$ \\
\hline & Uncertain & 11 & 7.8 & $7.8-7.9$ \\
\hline & No randomization & 5 & 3.6 & $3.6-3.7$ \\
\hline \multirow[t]{6}{*}{ Is the concealed randomization method specified? } & De-centralized & 73 & 51.8 & $51.4-52.4$ \\
\hline & Nontransparent envelopes with & 21 & 14.9 & $14.8-15.1$ \\
\hline & sequential opening ${ }^{\star}$ & 18 & 12.8 & $12.7-13.0$ \\
\hline & Other* $^{*}$ & 10 & 7.1 & $7.1-7.2$ \\
\hline & Not mentioned & 29 & 20.6 & $20.5-20.9$ \\
\hline & Inexistent & & & 은 \\
\hline \multirow[t]{5}{*}{ Type of control } & Placebo & 13 & 9.2 & $9.1-9.4$ \\
\hline & Active treatment* & 116 & 82.2 & $81.5-83.1$ \\
\hline & No treatment* & 12 & 8.5 & $8.5-8.6$ \\
\hline & Not indicated & 1 & 0.7 & $0.7-0.7$ \\
\hline & Other & 1 & 0.7 & $0.7-0.7$ \\
\hline \multirow[t]{6}{*}{ Is the degree of assessment concealment indicated? } & Open or non-blinded & 17 & 11.9 & $11.8-12.1$ \\
\hline & Single-blind & 18 & 12.8 & $12.7-13.0$ \\
\hline & Double-blind & 10 & 7.1 & $7.1-7.2$ \\
\hline & Blinded assessment by third parties & 26 & 18.4 & $18.3-18.7$ \\
\hline & Triple-blind & 6 & 4.3 & $4.3-4.4$ \\
\hline & Not indicated & 64 & 45.4 & $45.0-\frac{45.9}{2}$ \\
\hline \multirow[t]{4}{*}{ Is it explained why the trial is not blind? } & Yes & 14 & 9.9 & $9.8-1 \overline{0} .1$ \\
\hline & No & 58 & 41.1 & $40.8-41.6$ \\
\hline & Uncertain & 10 & 7.1 & $7.1-7.2$ \\
\hline & There is blinding & 59 & 41.8 & $41.5-42.3$ \\
\hline \multirow[t]{4}{*}{ Is the blinding method indicated? } & Yes & 31 & 22.0 & $21.8-22.3$ \\
\hline & No & 22 & 15.6 & $15.5-15.8$ \\
\hline & Uncertain & 8 & 5.7 & $5.7-5.8$ \\
\hline & There is no blinding & 80 & 56.7 & $56.2-57.4$ \\
\hline
\end{tabular}


Table 1. Description of the sample and methodological variables: frequencies, percentages and $95 \%$ confidence intervals (Continued)

\begin{tabular}{|c|c|c|c|c|}
\hline Variable & Value & Frequency & $\%$ & $95 \% \mathrm{Cl}$ \\
\hline \multirow[t]{4}{*}{ Type of treatment } & Already marketed drug & 10 & 7.1 & $7.1-7.2$ \\
\hline & Medical device & 5 & 3.6 & $3.6-3.7$ \\
\hline & Medical intervention method* & 73 & 51.8 & $51.4-52.4$ \\
\hline & Other: water aerobics, yoga...* & 53 & 37.6 & $37.3-38.1$ \\
\hline \multirow[t]{9}{*}{ Trial result } & Treatment significantly better & & & \\
\hline & Difference by author (s), but not & 50 & 35.5 & $35.2-35.9$ \\
\hline & significant & 22 & 15.6 & $15.5-15.8$ \\
\hline & Trend towards treatment & & & \\
\hline & Uncertain & 12 & 8.5 & $8.5-8.6$ \\
\hline & No difference & 1 & 0.7 & $0.7-0.7$ \\
\hline & Trend towards control & 44 & 31.2 & $31.0-31.6$ \\
\hline & Control significantly better & 1 & 0.7 & $0.7-0.7$ \\
\hline & $\begin{array}{l}\text { Other: significant improvement in a } \\
\text { primary variable }\end{array}$ & 3 & 2.1 & $2.1-2.2$ \\
\hline \multirow[t]{8}{*}{ Response assessment (endpoint) } & Death & 8 & 5.7 & $5.7-5.8$ \\
\hline & Laboratory diagnosis & 3 & 2.1 & $2.1-2.2$ \\
\hline & Symptomatic diagnosis* & 21 & 14.9 & $14.8-15.1$ \\
\hline & Other: sphygmomanometer, medical & 5 & 3.6 & $3.6-3.7$ \\
\hline & records...* & 55 & 39.0 & $38.7-39.5$ \\
\hline & Inexistent & 1 & 0.7 & $0.7-0.7$ \\
\hline & Questionnaire* $^{*}$ & 16 & 11.2 & 11.1-11.4 \\
\hline & Measuring scale* & & & \pm \\
\hline
\end{tabular}

or no intervention produced additional risk of serious and irreversible harm. The clinical trial was reproducible in all cases but in two, and in one it was uncertain. In 48 studies there were concomitant treatments (allowed or not), and in 68 the intervention was innocuous. In $31.2 \%$ (95\% Cl: 31.0-31.6), serious adverse events were observed in general (even deaths) and were uncertain in 21 studies. Intent-to-treat analysis was carried out in 64 clinical trials, it was not indicated (it was performed, but not mentioned) in 7 and it was uncertain (it was mentioned but not adequately performed) in 6. According to Jadad score, 70 trials had good quality ( 3 or 4 ) 54 , low quality (1or 2 ) and 11 , excellent (5).

When the "Trial development and response assessment" section was analyzed, the primary outcome variable (endpoint) was not described in 3 clinical trials and it was uncertain in $9.2 \%(95 \% \mathrm{Cl}$ : 9.1-9.4). In 139 clinical trials, statistical methods to assess the results were specified. Multivariate analysis was applied in $61.7 \%$ (95\% Cl: 61.2-62.4), and the number needed to treat only in 4. A DSMB was found in $5.7 \%$ (95\% Cl: 5.7-5.8). Changes to the protocol during the clinical trial were made in 9, with the CREC additionally being informed about it in 3. Finally, 29.1\% (95\% Cl: 28.9-29.5) were observed to follow the CONSORT guidelines.

The most important ethical variables are shown in table 4. In 7 studies, only the Helsinki Declaration was taken into account (lower quality than approval by a CREC), and one study was published not indicating to have followed it (very low ethical quality). In 9 clinical trials, individuals who were candidates to be included were observed to have received partial information on the objectives, funding, etc. of the clinical trial, and in 8 clinical trials, it was not clearly verified that this information was understood ${ }^{19}$.

Participating subjects that were minors of age were found in 14 clinical trials. Parents or legal guardians granted informed consent in 4 clinical trials, with this not being clearly established in 10 . In $2.8 \%(95 \% \mathrm{Cl}$ : 2.8-2.9), minors participated as a necessary characteristic of the study, and it was uncertain in $7.1 \%$ (95\% Cl: 7.1-7.2).

Participating subjects' personal information confidentiality was observed to be protected in $44.7 \%$ ( $95 \%$ Cl: 44.3-45.2), and in no study was the possibility of keeping these data for future use included in the informed consent. Harm to participating subjects was shown by $4.3 \%$ (95\% Cl: $4.3-4.4$ ) of studies, but there was no indication of any compensation. In one clinical trial, the protocol referred to the repair of potentially sustained harm in order for not being left with sequels, and in 2 clinical trials, there were arrangements in order for potential harm to ultimately equate to the potential beneficial result in all participating subjects. In addition, in $32.6 \%$ (95\% Cl: 32.4-33.0) no study protocol was mentioned. Five clinical trials provided the most 
Gaceta Médica de México. 2018;154

Table 2. Quality of information for quantitative variables: frequencies, percentages and $95 \%$ confidence intervals

\begin{tabular}{|c|c|c|c|}
\hline Variable: quality of information & Frequency & $\%$ & $95 \% \mathrm{Cl}$ \\
\hline Assessed subjects & & & $\stackrel{\infty}{-}$ \\
\hline Mentioned in article & 114 & 80.9 & $80.2-81.8$ \\
\hline Calculated or implicitly understood by the reader & 8 & 5.7 & $5.7-5.8$ \\
\hline Omitted and incalculable & 17 & 11.9 & $11.8-12.1$ \\
\hline Eligible subjects not shown & 2 & 1.4 & $1.4-1.5$ \\
\hline \multicolumn{4}{|l|}{ Assessed subjects (cluster) } \\
\hline Mentioned in article & 35 & 24.8 & $24.6-25.1$ \\
\hline Calculated or implicitly understood by the reader & 5 & 3.6 & $3.6-3.7$ \\
\hline Omitted and incalculable & 4 & 2.8 & $2.8-2.9$ \\
\hline Not a cluster-type clinical trial & 97 & 68.8 & $68.2-69.6$ \\
\hline \multicolumn{4}{|l|}{ Subjects refusing to participate } \\
\hline Mentioned in article & 48 & 34.1 & $33.8-34.6$ \\
\hline Calculated or implicitly understood by the reader & 72 & 51.1 & $50.7-51.7$ \\
\hline Omitted and incalculable & 19 & 13.5 & $13.4-13.7$ \\
\hline Not shown & 2 & 1.4 & $1.4-1.5$ \\
\hline \multicolumn{4}{|l|}{ Subjects refusing to participate (cluster) } \\
\hline Mentioned in article & 16 & 11.3 & $11.2-11.5$ \\
\hline Calculated or implicitly understood by the reader & 24 & 17.0 & $16.9-17.2$ \\
\hline Omitted and incalculable & 4 & 2.8 & $2,8-2,9$ \\
\hline Not a cluster-type clinical trial & 97 & 68.8 & $68.2-69.6$ \\
\hline \multicolumn{4}{|l|}{ Randomized patients } \\
\hline Mentioned in article & 116 & 82.3 & $81.6-83.2$ \\
\hline Calculated or implicitly understood by the reader & 19 & 13.5 & $13.4-13.7$ \\
\hline Omitted and incalculable & 3 & 2.1 & 2.1-2.2 \\
\hline Not shown & 3 & 2.1 & $2.1-2.2$ \\
\hline \multicolumn{4}{|l|}{ Randomized subjects (cluster) } \\
\hline Mentioned in article & 33 & 23.4 & $23.2-23.7$ \\
\hline Calculated or implicitly understood by the reader & 10 & 7.1 & $7.1-7.2$ \\
\hline Omitted and incalculable & 1 & 0.7 & $0.7-0.7$ \\
\hline Not a cluster-type clinical trial & 97 & 68.8 & $68.2-69.6$ \\
\hline \multicolumn{4}{|l|}{ Received assigned treatment } \\
\hline Mentioned in article & 71 & 50.4 & $50.0-51.0$ \\
\hline Calculated or implicitly understood by the reader & 64 & 45.4 & $45.0-45.9$ \\
\hline Omitted and incalculable & 6 & 4.3 & $4.3-4.4$ \\
\hline \multicolumn{4}{|l|}{ Received assigned treatment (cluster) } \\
\hline Mentioned in article & 20 & 14.2 & $14.1-14.4$ \\
\hline Calculated or implicitly understood by the reader & 23 & 16.3 & $16.2-16.5$ \\
\hline Omitted and incalculable & 1 & 0.7 & $0.7-0.7$ \\
\hline Not a cluster-type clinical trial & 97 & 68.8 & $68.2-69.6$ \\
\hline \multicolumn{4}{|l|}{ Withdrew informed consent } \\
\hline Mentioned in article & 22 & 15.6 & $15.5-15.8$ \\
\hline Calculated or implicitly understood by the reader & 78 & 55.3 & $54.8-55.9$ \\
\hline Omitted and incalculable & 16 & 11.3 & $11.2-11.5$ \\
\hline There is no informed consent & 25 & 17.7 & $17.6-18.0$ \\
\hline \multicolumn{4}{|l|}{ Withdrew informed consent (cluster) } \\
\hline Mentioned in article & 6 & 4.3 & $4.3-4.4$ \\
\hline Calculated or implicitly understood by the reader & 25 & 17.7 & $17.6-18.0$ \\
\hline Omitted and incalculable & 4 & 2.8 & $2.8-2.9$ \\
\hline $\begin{array}{l}\text { There is no informed consent or not a cluster-type } \\
\text { clinical trial }\end{array}$ & 106 & 75.2 & $74.5-76.0$ \\
\hline \multicolumn{4}{|l|}{ Losses to follow-up } \\
\hline Mentioned in article & 24 & 17.0 & $16.9-17.2$ \\
\hline Calculated or implicitly understood by the reader & 92 & 65.2 & $64.6-65.9$ \\
\hline Omitted and incalculable & 25 & 17.7 & $17.6-18.0$ \\
\hline
\end{tabular}


Table 2. Quality of information for quantitative variables: frequencies, percentages and $95 \%$ confidence intervals (Continued)

\begin{tabular}{|c|c|c|c|}
\hline Variable: quality of information & Frequency & $\%$ & $95 \% \mathrm{Cl}$ \\
\hline Losses to follow-up (cluster) & & & $\stackrel{\infty}{-}$ \\
\hline Mentioned in article & 13 & 9.2 & $9.1-9.4$ \\
\hline Calculated or implicitly understood by the reader & 24 & 17.0 & $16.9-17.2$ \\
\hline Omitted and incalculable & 6 & 4.3 & $4.3-4.4$ \\
\hline Not shown or not a cluster-type clinical trial & 98 & 69.5 & $68.9-70.3$ \\
\hline \multicolumn{4}{|l|}{ Main analysis over one total } \\
\hline Mentioned in article & 62 & 44.0 & $43.6-44.5$ \\
\hline Calculated or implicitly understood by the reader & 75 & 53.2 & $52.8-53.8$ \\
\hline Omitted and incalculable & 4 & 2.8 & 2.8-2.9 \\
\hline \multicolumn{4}{|l|}{ Main analysis over one total (cluster) } \\
\hline Mentioned in article & 12 & 8.5 & $8.5-8.6$ \\
\hline Calculated or implicitly understood by the reader & 28 & 19.9 & $19.8-20.2$ \\
\hline Omitted and incalculable & 3 & 2.1 & $2.1-2.2$ \\
\hline Not shown or not a cluster-type clinical trial & 98 & 69.5 & $68.9-70.3$ \\
\hline \multicolumn{4}{|l|}{ Cases with endpoints desired to be avoided } \\
\hline Mentioned in article & 8 & 5.7 & $5.7-5.8$ \\
\hline Calculated or implicitly understood by the reader & 40 & 28.4 & $28.2-28.8$ \\
\hline Omitted and incalculable & 92 & 65.2 & $64.6-65.9$ \\
\hline There is no endpoint & 1 & 0.7 & $0.7-0.7$ \\
\hline Cases with endpoints desired to be avoided (cluster) & 5 & 3.6 & $3.6-3.7$ \\
\hline Mentioned in article & 37 & 26.2 & $26.0-26.5$ \\
\hline Calculated or implicitly understood by the reader & 99 & 70.2 & $69.6-71.0$ \\
\hline Omitted and incalculable & & & $\overline{0}$ \\
\hline
\end{tabular}

Table 3. Qualitative variables most representative statistics

\begin{tabular}{|c|c|c|c|c|c|c|}
\hline & Mean & Median & Mode & Minimum & Maximum & Standard deviation $(95 \% \mathrm{Cl})$ \\
\hline Assessed subjects & 9098.15 & 641.00 & 91 (several) & 32 & 572546 & $53871.94(48233.54-61015.48)$ \\
\hline Assessed subjects (cluster) & 108.68 & 69.50 & 40 & 9 & 373 & $95.02(85.07-107.62)$ \\
\hline Subjects refusing to participate & 363.08 & 3.00 & 0 & 0 & 18882 & $1936.66(1733.96-2193.46)$ \\
\hline Subjects refusing to participate (cluster) & 25.34 & 0.00 & 0 & 0 & 203 & $53.44(47.85-60.53)$ \\
\hline Randomized subjects & 1150.84 & 280.00 & 125 (several) & 11 & 38147 & $3936.06(3524.10-4457.99)$ \\
\hline Randomized subjects (cluster) & 107.58 & 51.00 & 45 (several) & 9 & 1361 & $211.22(189.11-239.23)$ \\
\hline Received assigned treatment & 1161.22 & 289.00 & 237 & 11 & 38147 & $4057.90(3633.19-4595.99)$ \\
\hline Received assigned treatment (cluster) & 101.35 & 51.00 & 41 & 9 & 1361 & $208.97(187.10-236.68)$ \\
\hline Withdrew informed consent & 4.22 & 0.00 & 0 & 0 & 97 & $14.20(12.71-16.08)$ \\
\hline Withdrew consent (cluster) & 0.74 & 0.00 & 0 & 0 & 16 & $3.10(2.77-3.51)$ \\
\hline Losses to follow-up & 74.78 & 13.00 & 0 & 0 & 1612 & $233.09(208.69-264.00)$ \\
\hline Losses to follow-up (cluster) & 4.11 & 0.00 & 0 & 0 & 54 & $9.92(8.88-11.23)$ \\
\hline Main analysis over one total & 1062.51 & 234.00 & 164 & 11 & 36092 & $3864.55(3460.07-4377.00)$ \\
\hline Main analysis on one total (cluster) & 100.95 & 47.00 & 40 & 9 & 1361 & $216.22(193.59-244.89)$ \\
\hline $\begin{array}{l}\text { Cases with endpoints desired to be } \\
\text { avoided }\end{array}$ & 181.46 & 73.00 & 0 & 7 & 1912 & $348.60(312.11-394.82)$ \\
\hline $\begin{array}{l}\text { Cases with endpoints desired to be } \\
\text { avoided (cluster) }\end{array}$ & 3.20 & 0.00 & 0 & 0 & 16 & $7.15(6.40-8.10)$ \\
\hline
\end{tabular}


Gaceta Médica de México. 2018;154

Table 4. Ethical variables: frequencies, percentages and $95 \%$ confidence intervals

\begin{tabular}{|c|c|c|c|c|}
\hline Variable & Value & Frequency & $\%$ & $95 \% \mathrm{Cl}$ \\
\hline \multirow[t]{2}{*}{ Is it mentioned if informed consent was obtained? } & Yes & 111 & 78.7 & $78.0-79.6$ \\
\hline & No & 30 & 21.3 & $21.2-21.6$ \\
\hline \multirow[t]{3}{*}{ Was informed consent voluntarily obtained? } & Yes & 10 & 7.1 & $71-7.2$ \\
\hline & Uncertain & 101 & 71.6 & $71.0-72.4$ \\
\hline & No informed consent was obtained & 30 & 21.3 & $21.2-21.6$ \\
\hline \multirow{4}{*}{$\begin{array}{l}\text { Is the type of informed consent specified, and } \\
\text { whether it is witnessed and documented? }\end{array}$} & Verbal (no witness mentioned) & 1 & 0.7 & $0.7-0.7$ \\
\hline & Written & 69 & 48.9 & $48.5-49.5$ \\
\hline & Not mentioned (if written or verbal) & 41 & 29.1 & 28.9-29.5 \\
\hline & No informed consent was obtained & 30 & 21.3 & $21.2-21.6$ \\
\hline \multirow{3}{*}{$\begin{array}{l}\text { Did the patient receive information when obtaining the } \\
\text { informed consent? }\end{array}$} & Yes & 43 & 30.5 & $30.3-30.9$ \\
\hline & No & 68 & 48.2 & $47.8-48.8$ \\
\hline & No informed consent was obtained & 30 & 21.3 & $21.2-21.6$ \\
\hline \multirow{4}{*}{$\begin{array}{l}\text { Was informed consent obtained under a dependence } \\
\text { relationship or under pressure? }\end{array}$} & Dependence relationship & 44 & 31.2 & $31.0-31.6$ \\
\hline & No & 14 & 9.9 & $9.8-10.1$ \\
\hline & Uncertain & 53 & 37.6 & $37.3-38.1$ \\
\hline & No informed consent was obtained & 30 & 21.3 & $21.2-21.6$ \\
\hline \multirow{4}{*}{$\begin{array}{l}\text { Was an unrelated qualified person appointed to } \\
\text { obtain informed consent? }\end{array}$} & Yes & 2 & 1.4 & $1.4-1.5$ \\
\hline & No & 35 & 24.8 & $24.6-25.1$ \\
\hline & Uncertain & 60 & 42.6 & $42.3-43.1$ \\
\hline & $\begin{array}{l}\text { No informed consent or not under pressure or } \\
\text { dependence }\end{array}$ & 44 & 31.2 & $31.0-31.6$ \\
\hline \multirow{4}{*}{$\begin{array}{l}\text { Was informed consent of the participating subject } \\
\text { withdrawn anytime during the clinical trial? }\end{array}$} & Yes & 21 & 14.9 & $14.8-15.1$ \\
\hline & No & 79 & 56.0 & $55.5-56.7$ \\
\hline & Uncertain & 11 & 7.8 & $7.8-7.9$ \\
\hline & No informed consent was obtained & 30 & 21.3 & $21.2-21.6$ \\
\hline \multirow{6}{*}{$\begin{array}{l}\text { Any incentive for investigators, participating centers } \\
\text { or subjects? }\end{array}$} & No & 96 & 68.1 & $67.5-68.9$ \\
\hline & To investigators & 26 & 18.4 & 18.3-18.7 \\
\hline & To participating centers & 4 & 2.8 & $2.8-2.9$ \\
\hline & To participating subjects* & 16 & 11.2 & $1.1 .1-11.4$ \\
\hline & To investigator assistants* & 6 & 4.3 & $4.3-4.4$ \\
\hline & To participating physicians (cluster)* & 7 & 5.0 & $5.0-5.1$ \\
\hline \multirow[t]{7}{*}{ If the answer is affirmative, specify type and amount } & Bonus to investigators & 7 & 5.0 & $5.0-5.1$ \\
\hline & Subsidy or grant to investigators* & 23 & 16.3 & $16.2-16.5$ \\
\hline & Bonus to participating centers & 4 & 2.8 & $2.8-2.9$ \\
\hline & Bonus to subjects for participating* & 16 & 11.2 & 11.1-11.4 \\
\hline & Bonus to assistants* & 6 & 4.3 & $4.3-4.4$ \\
\hline & Bonus to physicians (cluster) for participating* & 7 & 5.0 & $5.0-5.1$ \\
\hline & No incentives were given & 96 & 68.1 & $67.5-68.9$ \\
\hline \multirow[t]{3}{*}{ Has the given incentive been proportionate? } & Yes & 41 & 29.1 & $28.9-29.5$ \\
\hline & No & 4 & 2.8 & $2.8-2.9$ \\
\hline & No incentives were given & 96 & 68.1 & $67.5-68.9$ \\
\hline \multirow{5}{*}{$\begin{array}{l}\text { Provided information with regard to conflicts of } \\
\text { interests }\end{array}$} & There is no conflict of interests & 117 & 83.0 & $82.2-83.9$ \\
\hline & Remuneration or grant from company & 12 & 8.5 & 8.5-8.6 \\
\hline & Any author works for company* & 14 & 9.9 & $9.8-10.1$ \\
\hline & Other: author was consultant or owner* & 7 & 5.0 & $5.0-5.1$ \\
\hline & Any author is stockholder of the company & 1 & 0.7 & $0.7-0.7$ \\
\hline
\end{tabular}

* Sum of the same result in several identical variables.

beneficial intervention to the rest of participating subjects after their conclusion, but only in one case was that possibility specified in the informed consent. Study general results were shown to all participants at its conclusion in $1.4 \%$ (95\% Cl: $1.4-1.5)$ of studies.
No study referred specific bioethics training of the authors. All clinical trials informed about potential conflicts of interests. Sponsor influence was not described in $57.4 \%$ (95\% Cl: 56.9-58.1). Analyzed studies were registered (in ClinicalTrials.gov or similar, according 
to the country of study) in $55.3 \%(95 \% \mathrm{Cl}$ : 54.8-55.9).

Among 112 comparable variables, a $\kappa$ mean of 0.96 (95\% Cl: 0.93-0.99) was obtained.

\section{Discussion}

It is possible claiming that the type of clinical trial most commonly published in the 10 reviewed journals is multi-center, publicly funded, controlled, parallel, of simple randomized design, with de-centralized concealed randomization, using an active treatment as control, with a 12-month duration, in Caucasian patients and with a medical intervention method, with a positive result in $50 \%$ (measured by means of a questionnaire). In $45 \%$, intent-to-treat analysis is carried out. Serious adverse effects and good quality are shown (Jadad 3). In addition, informed consent (verbal or not mentioned), lack of incentives and non-existence of conflicts of interests appear more often than in other referred publications.

On the other hand, the checklist used in this analysis has more items than the CONSORT list in order to consider specific aspects where CONSORT has not sufficient impact according to our opinion. In addition, by basing ourselves on the latest Declaration of Helsinki, we delved even more into different ethical aspects than the CONSORT guidelines, which, in our opinion, do not consider them sufficiently.

If we make a comparative analysis with the clinical trials of the study performed about the New England Journal of Medicine, British Medical Journal, Journal of the American Medical Association and Lancet journals ${ }^{17}$, we find that concealed randomization has progressively increased: from $33.1 \%$ in $1993-1995$ to $56.7 \%$ in $2004^{17}$, and even more in our study. This might be explained by the fact that after CONSORT, it was much insisted that this type of assignment was essential to reduce selection bias. In contrast, double blinding is less common than in previous reviews (43.9\% in $1993-1995$ and $43.3 \%$ in 2004$)^{17}$, and the use of placebo as control has also been decreasing $(37.0 \% \text { in } 1993-1995 \text { and } 16.7 \% \text { in 2004) })^{17}$, and even less in our study, probably because, over the years, there are more standard treatments to compare and higher demands of regulatory authorities for considering new treatments launch into the market, with their efficacy having to be demonstrated with already standardized treatments.

With regard to ethical quality indicators, the number of clinical trials where reference to one CREC and more appears has increased in recent years: $25.5 \%$ in 1993-1995 and 20\% in 2004 ${ }^{17}$. Clinical trials with children and disabled subjects are very rare, probably because these are articles about clinical trials published in primary care and internal medicine journals.

Sinha et al. ${ }^{29}$ obtained a Jadad score $\geq 3$ in $40 \%$ of 42 clinical trials ${ }^{29}$, which is an inferior result to ours.

Agha et al. ${ }^{30}$ concur with us with their sample of 57 clinical trials, on that the USA (with 15 studies) is the country where clinical trials are more commonly carried out.

Public funding was most common in 74 clinical trials assessed by Lai et al. ${ }^{31}$, just as in our study, probably because clinical trials are highly expensive. In addition, important adverse effects are more common (64.9\%; 95\% Cl: 52.9-75.6) than in our study, probably because they did not study innocuous medical interventions, but more aggressive treatments. Methodological quality is also higher in our study since, in their review ${ }^{31}$, the primary variable only appears in $45.9 \%$ (95\% Cl: 34.3-57.9), sample size calculation in $39.2 \%$ (95\% Cl: $28.0-51.2)$, concealed randomization in $29.7 \%(95 \% \mathrm{Cl}: 19.7-41.5)$, blinding in $2.2 \%(95 \%$ Cl: $4.5-19.8)$ and intent-to-treat analysis in $27 \%$ (95\% Cl: 16.7-37.4).

Comparing different methodological quality aspects of our study with others recently conducted in other specialties, we can highlight the following. In a review of 300 cluster-type clinical trials ${ }^{32}, 55 \%$ wrote about sample size calculation (a lower figure than in our review). In another review ${ }^{33}$ of 89 randomized clinical trials about endodontics, a lower percentage was found in comparison with our study, since only $45 \%$ generated a randomization sequence to reduce bias risk, $75 \%$ provided no information on the assignment method and $19.1 \%$ had a non-blinded design. Furthermore, only $55 \%$ had adequately carried out the sample size estimation, only $16 \%$ obtained confidence intervals and $25 \%$ did not report the $p$-value. Finally, $2.2 \%$ did not perform statistical tests. In the field of orthopedics, in a review of 222 studies $^{34}$, in none of them was the sample size adequately calculated, in $33.4 \%$ was there an adequate randomization sequence generated, only in $3.7 \%$ was randomization correctly performed and in $8.1 \%$ was there an adequate blinding (figures that are inferior to those in our review). Specifically, in the 8 articles chosen from the Orthopaedics Traumatology Surgery \& Research journal, $12.5 \%$ were found not to mention having performed an adequate randomization sequence, in $50 \%$ was not a correct 
randomization reported and in $25 \%$ was there an adequate blinding (figures that are inferior to ours as well). In the field of the respiratory system, in a review of 176 trials $^{35}, 53 \%$ were found to mention adequate generation of a randomization sequence, in $38 \%$ was randomization correct, $45 \%$ were double-blinded, in $70 \%$ was sample size calculation adequate, in $50 \%$ was there an intent-to-treat analysis carried out and $69 \%$ included a flow diagram. Except for the double blinded percentage, the rest of the figures are quite inferior to those found in our review. In a review of 305 studies published in journals about diabetes ${ }^{36}$, the authors found that $35.4 \%$ of trials showed an adequate randomization sequence generation, in $28.5 \%$ was randomization correct and in $23.8 \%$ was there an intent-to-treat analysis carried out (which are lower percentages to those found in our study). In a review of 321 articles on epidural anesthesia ${ }^{37}$, the authors found a Jadad score mean value of 2 (lower than that observed in our review) and a general increase in methodological quality in those articles published after the CONSORT guidelines appearance, which is consistent with our review. In the field of transplantations, the authors of a review ${ }^{38}$ of 290 studies found that $43 \%$ had good quality according to Jadad scale (a figure a bit lower than ours) and, in one third of these, randomization and data analysis were satisfactory (quite lower than that which was observed in our study). In addition, methodological quality and adherence to CONSORT guidelines were higher in trials of journals that were in compliance with $\mathrm{CONSORT}^{38}$. In colorectal cancer treatment, the authors of a review ${ }^{39}$ found quite inferior data to ours in 40 randomized clinical trials, since only $7.5 \%$ were identified as randomized clinical trials in the title, and also only $7.5 \%$ applied a randomization method to the sequences, only $5 \%$ mentioned the randomization type and only $2.5 \%$ applied a concealment method or calculated the sample size. Only $2.5 \%$ described the flow diagram and primary and secondary outcome variables with estimated sample effect. Finally, $32.5 \%$ showed baseline demographic and clinical characteristics, and $25 \%$ performed an intent-to-treat analysis. In a review ${ }^{40}$ of 53 clinical trials on multiple sclerosis, the authors found that $79 \%$ were sponsored by a pharmaceutical company, $13 \%$ had mixed funding and only $6 \%$ were funded by non-profit institutions. This might compromise the validity of this trial, since funding is clearly biased, just the opposite of what we found in our review. Mean assessed patients were 297 (range: $30-2244$ ); $83 \%$ of studies were placebo-controlled and did not show randomization systems. The statistical method used to generate the randomized list was specified by $81.1 \%$, with block randomization being most widely used (81.4\%). Double blinding was used by $90.6 \%$, and only one trial was not blinded. Among the trials with single blinding, $94.2 \%$ showed details about who had carried out the blinding and $59.6 \%$ about how it had been performed. All studies but two defined the primary outcome variable. Significantly positive trials were found to be $64.2 \%$. Intentto-treat analysis was used in $79.2 \%$. No CONSORT flow diagram was shown by $20.8 \%$. In 52 trials, the number of patients lost to follow-up was reported. All studies showed baseline characteristics in a table. Just as the above studies, data are less common, except for double blinding; the trials with positive significance and the sample of baseline characteristics are presented in a table. The authors of a review ${ }^{41}$ of 73 cluster-type clinical trials observed that $50 \%$ had been conducted in the USA or the United Kingdom (a percentage higher than that found by us). Sample size calculation was performed by $60 \%$. Information on patients lost to individual follow-up appeared in 53 trials, whereas on groups only in 28 . Blinded assessment by third parties appeared in $44 \%$ (a superior figure to that in our review). In 51 trials, a statistician appears as co-author (less than in our study), and this appearance, together to the publication period, has more influence on quality than the strength of the journal adherence to the CONSORT guidelines ${ }^{41}$. In a review $^{42}$ about immunosuppression in kidney transplantation, the authors observed that, in 179 studies, all had a parallel design. No funding source was declared or there wasn't any in 35\%,57\% were funded by the pharmaceutical industry, and $14 \%$ by a public entity (figures that are very different from those found in our review). Seventeen percent were multinational, with patients being recruited in more than one continent: $26 \%$ in North America, $44 \%$ in Europe, $7 \%$ in Asia and $11 \%$ in other zones (similar percentages to ours). In $67 \%$, the studies were published in journals that adhered to the CONSORT guidelines (a lower percentage than that in our study). The number of participating subjects ranged from 15 to 1645 . Two percent of studies showed $\leq 1$-month follow-up and $7 \% \leq 6$-mont follow-up results, with a range from 0.25 to 240 months (figures also lower to those found in our study).

Finally, if we compare our study with the one by Hopewell et al. ${ }^{7}$, we observe that, in the reviewed studies of 2006, the following appears: the primary outcome variable is defined in $53 \%$, sample size 
calculation in $45 \%$, the concealed randomization method employed in $34 \%$, the randomization method in $25 \%$, blinding appears in $59 \%$, flow diagram in $28 \%$, patients lost to follow-up in $69 \%$, intent-to-treat analysis in $31 \%$, pharmaceutical industry funding in $17 \%$ and clinical trial registry in $9 \%$.

As Baskerville et al. ${ }^{15}$, we only have been able to have access to clinical trials' published data and not to the original works, which could be different.

In our analysis there is important variability between studies regarding the measurement of the main variables, due to the many types that were found according to the study treatment.

As in the study by Hopewell ${ }^{7}$, we may have missed some articles in the search, since the indexation date in PubMed and other search engines has a certain delay with regard to the moment the article is published.

Furthermore, although we have performed an agreed pairwise evaluation with an optimal mean $\square$ coefficient, there is always the possibility of error in data collection when indicating item answers in the checklist used.

The creation of a checklist with so many items had the purpose to analyze methodological and ethical, general and quality characteristics, rather than being a regular tool for the review of clinical trials.

Finally, owing to space limitations we don't include the checklist used or its instructions, which could be available for readers if they desire.

\section{Conclusions}

After the publication of the CONSORT guidelines, general quality of published clinical trials has considerably increased, but there are some aspects that could be improved. Concealed randomization has increased by $19.6 \%^{17}$, and approval by a CREC by $75 \%{ }^{17}$, but double blinding has decreased by $36.2 \%{ }^{16}$, as well as the use of placebo to compare a new treatment by $7.5 \%{ }^{17}$ as methodological and ethical quality criteria, respectively, in clinical trials published in the 10 reviewed journals of the family medicine specialty (2010-2013).

\section{Conflict of interests}

The authors declare not having any conflicts of interests.

\section{References}

1. Guyatt $\mathrm{GH}$, Oxman $\mathrm{AD}$, Vist GE, et al. GRADE: an emerging consensus on rating quality of evidence and strength of recommendations. BMJ. 2008;336:924-6.

2. Pildal J, Chan AW, Hrobjartsson A, et al. Comparison of descriptions of allocation concealment in trial protocols and the published reports: cohort study. BMJ. 2005;330:1049-52.

3. Moher D, Altman DG, Schulz KF, et al. Opportunities and challenges for improving the quality of reporting clinical research: CONSORI and beyond. CMAJ. 2004;171:349-50.

4. Moher D, Hopewell S, Schulz KF, et al. CONSORT 2010 explanation and elaboration: updated guidelines for reporting parallel group randomised trials. BMJ. 2010;340:c869.

5. Dechartres A, Charles P, Hopewell S, Ravaud P, Altman DG. Reviews assessing the quality or the reporting of randomized controlled trials are increasing over time but raised questions about how quality is assessed.J Clin Epidemiol. 2011;64:136-44.

6. Cui $Q$, Tian J, Song X, et al. Does the CONSORT checklist for abstracts improve the quality of reports of randomized controlled trials on clinical pathways? J Eval Clin Pract. 2014;20:827-33.

7. Hopewell S, Dutton S, Yu LM, et al. The quality of reports of randomised trials in 2000 and 2006: comparative study of articles indexed in PubMed. BMJ. 2010;340:c723.

8. Campbell MK, Elbourne DR, Altman DG. CONSORT statement: extension to cluster randomised trials. BMJ. 2004;328:702-8.

9. Ahmed Ali U, van der Sluis PC, Issa Y, et al. Trends in worldwide volume and methodological quality of surgical randomized controlled trials. Ann Surg. 2013;258:199-207.

10. Moher D, Liberati A, Tetzlaff J, et al.; The PRISMA Group. Preferred reporting items for systematic reviews and meta-analyses: the PRISMA statement. PLoS Med. 2009;6:e1000097.

11. ISI Web of Knowledge. Journal Citations Reports. Thomson Reuters; 2014. (Consultado el 4 de febrero de 2014.) Disponible en: http://admin-apps.webofknowledge.com/JCR/JCR

12. Mills $E$, Wu $P$, Gagnier J, et al. The quality of randomized trial reporting in leading medical journals since the revised CONSORT statement. Contemporary Clin Trials. 2005;26:480-7.

13. Hooft L, Korevaar DA, Molenaar N, et al. Endorsement of ICMJE's clinical trial registration policy: a survey among journal editors. Neth $\mathrm{J}$ Med. 2014;72:349-55

14. Millum J, Wendler D, Emanuel EJ. The $50^{\text {th }}$ anniversary of the Declaration of Helsinki. Progress but many remaining challenges. JAMA. 2013;310:2143-4.

15. Baskerville NB, Liddy C, Hogg W. Systematic review and meta-analysis of practice facilitation within primary care settings. Ann Fam Med. 2012;10:63-74.

16. Bai Y, Gao J, Zou DW, Li ZS. Methodological reporting of randomized clinical trials in major gastroenterology and hepatology journals in 2006. Hepatology. 2009;49:2108-12.

17. Castaño García A. Evolución de la calidad de los ensayos clínicos publicados en 4 revistas generales de medicina (1993-5 y 2004). Un estudio preliminar. [Diploma de Estudios Avanzados]. Pamplona: Universidad de Navarra; 2005

18. Moher D, Schulz KF, Altman D; CONSORT Group (Consolidated Standards of Reporting Trials). The CONSORT statement: revised recommendations for improving the quality of reports of parallel-group randomized trials. JAMA. 2001;285:1987-91.

19. WMA.net. Declaración de Helsinki de la AMM. Principios éticos para las investigaciones médicas en seres humanos. Asociación Médica Mundial; 2014. (Consultado el 3 de abril de 2014.) Disponible en: http://www.wma. net/es/30publications/10policies/b3

20. Thorpe KE, Zwarenstein M, Oxman AD, et al. A pragmatic-explanatory continuum indicator summary (PRECIS): a tool to help trial designers. CMAJ. 2009;180:E47-57.

21. Gartlehner G, Hansen RA, Nissman D, et al. Criteria for distinguishing effectiveness from efficacy trials in systematic reviews. AHRQ Publication No. 06-0046; april 2006. (Consultado el 12 de enero de 2014.) Disponible en: http://archive.ahrq.gov/downloads/pub/evidence/pdf/efftrials/efftrials.pdf

22. Grant AM, Altman DG, Babiker AB, et al. Issues in data monitoring and interim analysis of trials. Health Technol Assess. 2005;9 (7).

23. Goldman B, LeBlanc M, Crowley J. Interim futility analysis with intermediate endpoints. J Clinical Trials. 2008;5:14-22.

24. AusVet Animal Health Services. Calculate confidence limits for a sample proportion. (Consultado el 16 de septiembre de 2014.) Disponible en: http://epitools.ausvet.com.au/content.php?page=CIProportion\&SampleSize $=141 \&$ Positive $=1 \&$ Conf $=0.95 \&$ Digits $=1$

25. Stats Calculator. Confidence interval calculator for means. McCallum Layton; 2014. (Consultado el 16 de septiembre de 2014.) Disponible en: https://www.allto.co.uk/tools/statistic-calculators/confidence-interval-for-mean-calculator/ 
26. Licciardone JC, Minotti DE, Gatchel RJ, et al. Osteopathic manual treatment and ultrasound therapy for chronic low back pain: a randomized controlled trial. Ann Fam Med. 2013;11:122-129.

27. Yank V, Rennie D. Reporting of informed consent and ethics committee approval in clinical trials. JAMA. 2002;287: 2835-8.

28. GraphPad Software. QuickCalcs. Confidence interval of a SD. (Consultado el 6 de diciembre de 2015.) Disponible en: http://graphpad.com/ quickcalcs/CISD1

29. Sinha S, Sinha S, Ashby E, et al. Quality of reporting in randomised trials published in high-quality surgical journals. J Am Coll Surg. 2009;209:565-71.e1.

30. Agha RA, Camm CF, Doganay E, et al. Randomised controlled trials in plastic surgery: a systematic review of reporting quality. Eur J Plast Surg. 2014;37:55-62.

31. Lai $R$, Chu $R$, Fraumeni $M$, et al. Quality of randomized controlled trials reporting in the primary treatment of brain tumors. J Clin Oncol. 2006;24:1136-44

32. Rutterford C, Taljaard M, Dixon S, et al. Reporting and methodologica quality of simple size calculations in cluster randomized trials could be improved: a review. J Clin Epidemiol. 2015;68:716-23.

33. Lucena C, Souza EM, Voinea GC, et al. A quality assessment of randomized controlled trials reports in endodontics. Int Endod J. 2017:50: 237-50.

34. Zhang J, Chen X, Zhu Q, et al. Methodological reporting quality of randomized controlled trials: a survey of seven core journals of orthopaedics from Mainland China over 5 years following the CONSORT statement. Orthop Traumatol Surg Res. 2016;102:933-8.
35. Lu Y, Yao Q, Gu J, et al. Methodological reporting of randomized clinical trials in respiratory research in 2010. Respir Care. 2013;58:1546-51.

36. Zhai $X$, Wang $Y, M u Q$, et al. Methodological reporting quality of randomized controlled trials in 3 leading diabetes journals from 2011 to 2013 following CONSORT statement: a system review. Medicine (Balt). 2015;94:e1083.

37. Liu SS, Togioka BM, Hurley RW, et al. Methodological quality of randomized controlled trials of postoperative epidural analgesia: validation of the Epidural Analgesia Trial Checklist as a specific instrument to evaluate methodology. Reg Anesth Pain Med. 2010;35:549-55.

38. Liu LQ, Morris PJ, Pengel LH. Compliance to the CONSORT statement of randomized controlled trials in solid organ transplantation: a 3-year overview. Transpl Int. 2013;26:300-6.

39. Huang D, Jin X, Gao J, et al. Quality evaluation of randomized controlled trials reports of laparoscopy compared with open colorectal resection for colorectal cancer. Expert Rev Anticancer Ther. 2015;15:727-32.

40. Signori A, Baccino A, Sormani MP. The quality of reports of randomized trials in multiple sclerosis: a review. Mult Scler. 2012;18:776-81.

41. Diaz-Ordaz K, Froud R, Sheehan B, et al. A systematic review of cluster randomised trials in residential facilities for older people suggests how to improve quality. BMC Med Res Methodol. 2013;13:127.

42. Masson P, Duthie FA, Ruster LP, et al. Consistency and completeness of reported outcomes in randomized trials of primary immunosuppression in kidney transplantation. Am J Transplant. 2013;13:2892-901. 